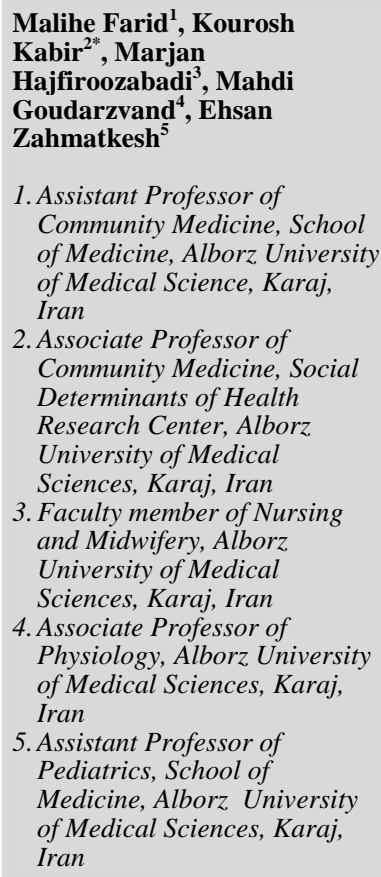

2. Associate Professor of Community Medicine, Social Determinants of Health Research Center, Alborz University of Medical Sciences, Karaj, Iran

3. Faculty member of Nursing and Midwifery, Alborz University of Medical Sciences, Karaj, Iran

4. Associate Professor of Physiology, Alborz University of Medical Sciences, Karaj, Iran

5. Assistant Professor of Pediatrics, School of Medicine, Alborz University of Medical Sciences, Karaj, Iran

\section{Patient Experiences of Hospital Stay in Alborz Governmental Hospitals}

Received:14 May 2017 ; Accepted:28 Nov. 2017

\section{Abstract}

Background and Aims: Attaining the patients' viewpoints and evaluating their experiences are reliable and important resources for determining the problems and appraising healthcare improvement. This study aimed to investigate the experiences of patients who hospitalized in hospitals of Alborz province.

Materials and Methods: In this descriptive cross-sectional study 955 patients discharged from nine governmental hospitals were selected by stratified random sampling method and participated in this study. The questionnaire that its validity and reliability had been confirmed was used to assess patients' experiences of hospital stay.

Results: More than half of the participants (56.4\%) were female. The most frequent age group (34.3\%) was the age group of 20 to 30 years. $45.4 \%$ of patients experienced a perfect organization in reception sector in emergency ward, and $42.5 \%$ of patients experienced a perfect organization in reception sector of non-emergency wards. In sum, $79.4 \%$ of patients assessed the hospital healthcare services in good level (or higher) and $35.9 \%$ stated that they would recommend the hospital to others.

Conclusion: The results indicates the need for designing and implementing the programs to improve patients' experiences in the areas of reception and discharge sectors organization, physical environment and facilities, communication with doctors and nurses, respectfulness, through training and empowerment of staff of hospitals and improving the existing infrastructure in the hospital.

Keywords: Hospital, Hospitalization, Experience, Patient
*Corresponding Author: Associate Professor of community Medicine, Social determinants of health research center, Alborz University of Medical Sciences, Karaj, Iran

Tel: 026- 34314400

E-mail: kabir.kourosh@yahoo.com 


\section{تجارب بيمار ان از بسترى در بيمار ستانهاى دولتى استان البرز}

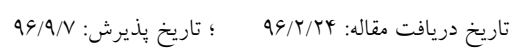

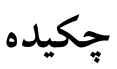

مقدمه: به دست آوردن نقطه نظرات بيماران و بررسى تجارب آنها به عنوان منبع معتبر و مهمى در ارزيابى كيفيت خــدمات

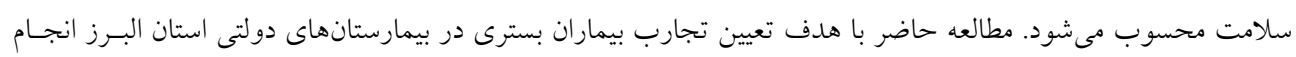
شده است. مواد و روشها: در اين مطالعه مقطعى - توصيفى 900 فرد تـرخيص شــه از 9 بيمارستان دولتسى استان البـرز در سـال

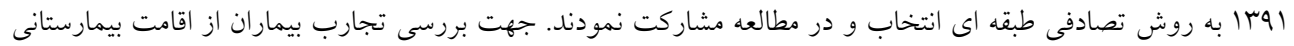

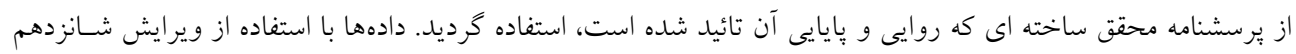
نرم افزار Spss موردتجزيه و تحليل قرار كرفتند.

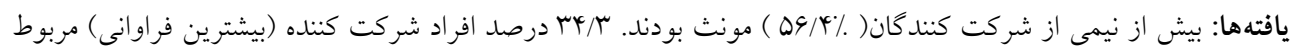

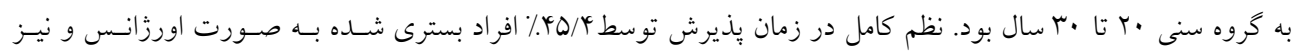

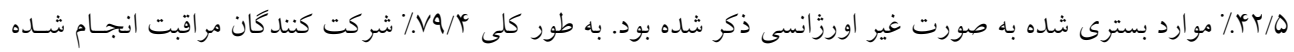

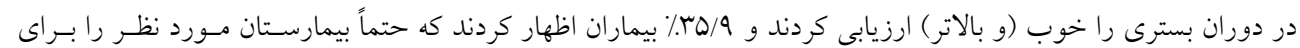
بسترى به ديخران توصيه مى كنند.

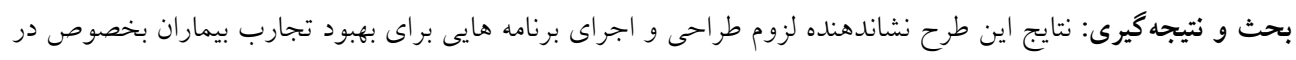

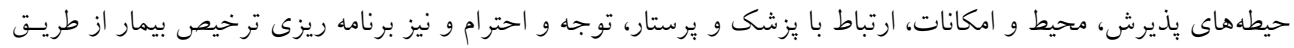

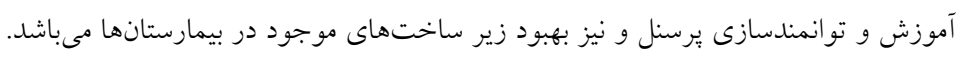
كلمات كليدى: بيمار ان، بيمارستان، بسترى، تجارب

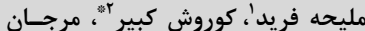

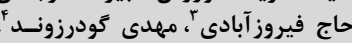

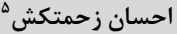

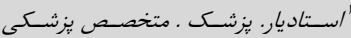

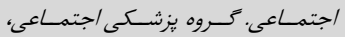

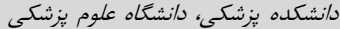

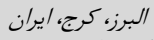

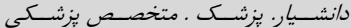

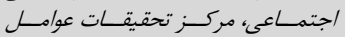

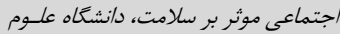

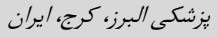

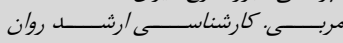

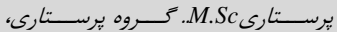

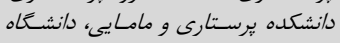
علوم يزشكى البرز، كرج، ايران

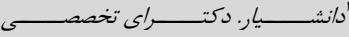

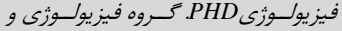
فارماكولوزىى، دانشكده برزشكى، دانشكاه

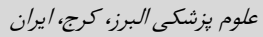

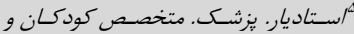

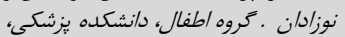
دانشَاه علوم بزشكى البرز، كرج، ايران

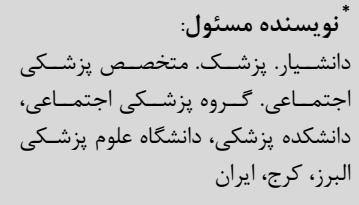

-réthtifa.

E-mail: kabir.kourosh@yahoo.com 
خود رفتار عمدى بيمار (بازگشت و توصيه به ديكران) را بيش بينى

امروزه كيفيت ارايه خدمات درمانى اهميـت روز افزونسى يافتـه

امروزه توجه افزايش يابنده اي در مورد ارزيابى رضايت بيماران

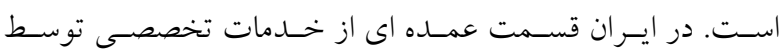

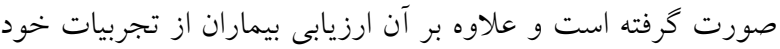

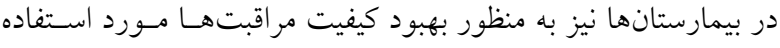

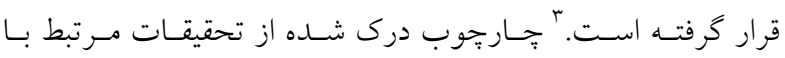

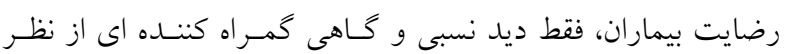
بيماران ايجاد مى كند و بررسى تجارب بيماران با سوالات جزئى تـر

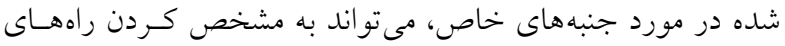

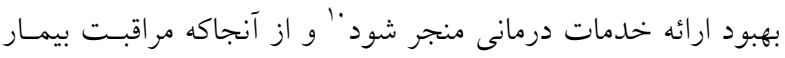

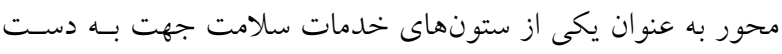

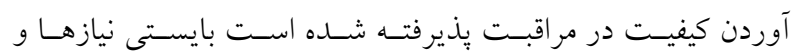
ترجيحات بيمار ان و نيز تجارب قبلى آنـان را مـورد ارزيـابى قـرار

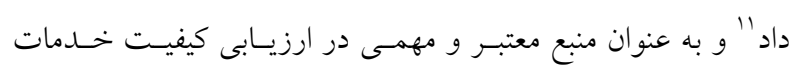

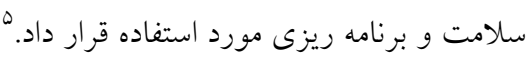

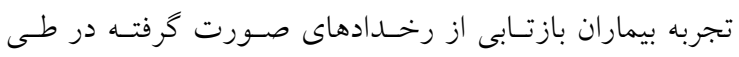

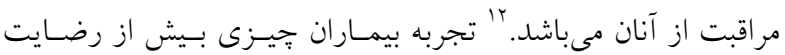
صرف آنان مىباشد و در مفهوم تجربه بيماران تمركز بر مراقبتهاى آنائ فردى سازى شده، متناسب كردن خدمات جهت تأمين نيـاز بيمـاران

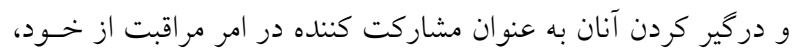

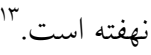

تجربه بيماران در ارتباطى تنخاتنخ با انتظارات آنان و اينكه آيـا به خوبى فهميده شده اند قرار مى گيرد. تجربه بيمـاران يكسى از سـه ستون كيفيت مراقبت سلامت در كنار ايمنى بيمار و اثربخشى بالينى مى باشد. مطالعات نشان داده اند كه ارتباط مثبتى بين تجارب بناب بيماران

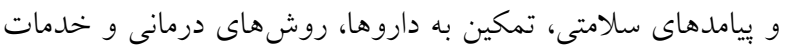

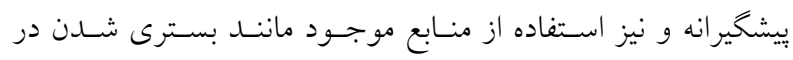
بيمارستان وجود دارد.

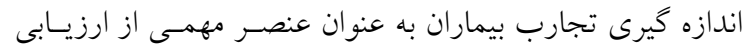

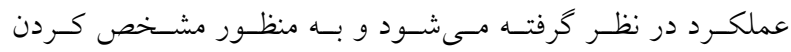

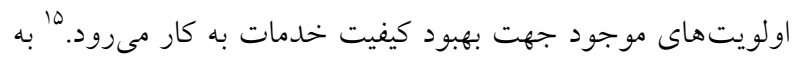

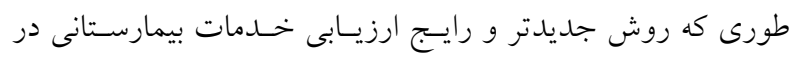
حال حاضر مطالعه تجارب بيماران مى باشد. مطالعه تجارب بيمـاران

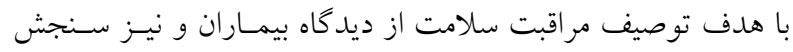

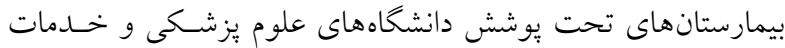
بهداشتى - درمانى ارايه مى كـردد. از طرفى ارزيـابى هـاى اعتبـار

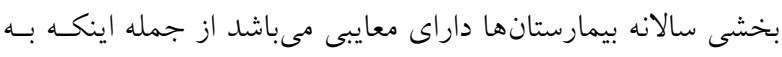

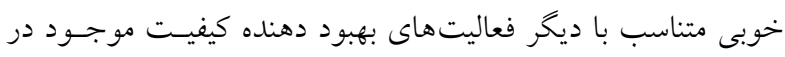

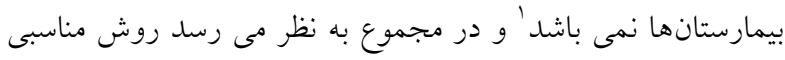

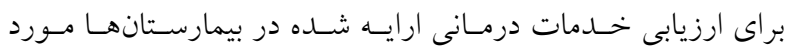
استفاده قرار نمى كيرد. سنجش كيفيت خدمات ارائه شده از اصـول

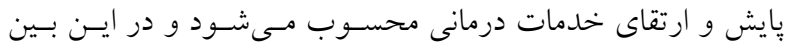

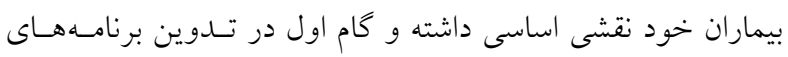
ارزشيابى و ارتقاى كيفيت، شناخت ادراكها و انتظـارات كيرنــــان

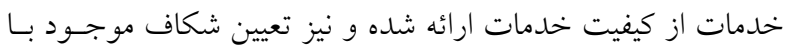

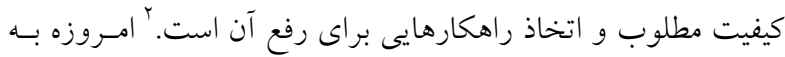

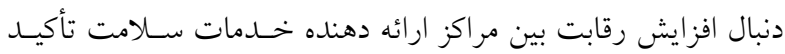

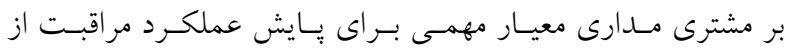

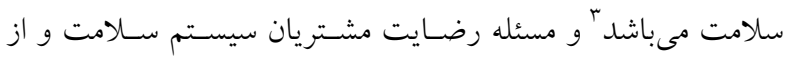

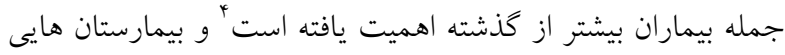

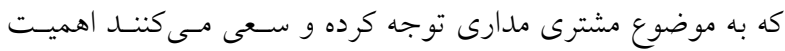

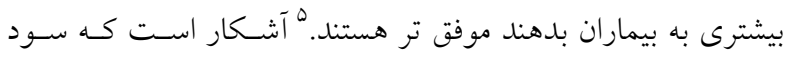

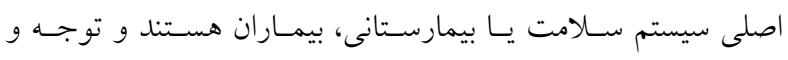
تمركز سيستمهاى بيمارستانى بر بيمـاران، بـه عنـوان مشـتريان ايـن فئس

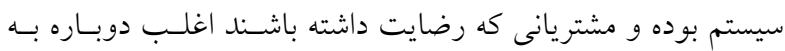

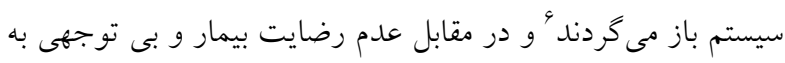

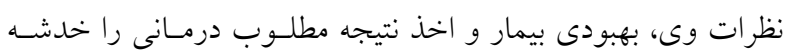

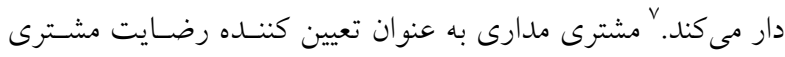

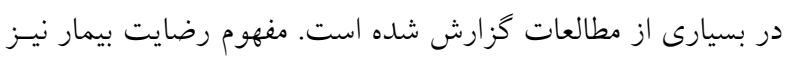
بسيار بيجيديده بوده و تحت تأثير فرهنگ، شناخت و احساسـات وى

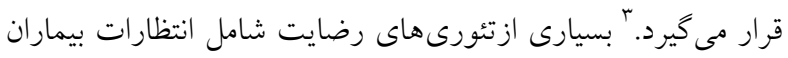

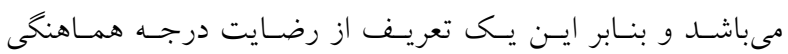

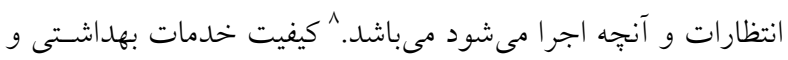

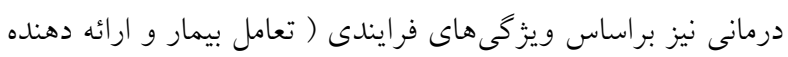

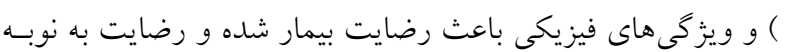


جمعيت شناختى مى باشد. برسشنامه ها به صورت خود ايفـا توسط بيمـاران يـا همــراه بيمـاران (در صـورت نـاتوانى فــــد در تكميـل

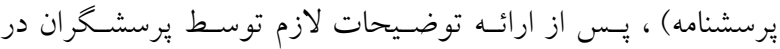
خصـوص هـدف از مطالعسه و كسـب رضـايت جهــت شـركت در مطالعه، تكميل شدند. در نهايت تمامى اطلاعات جمـع آورى شــده

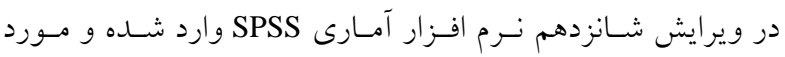
تجزيه و تحليل قرار گرفتند.

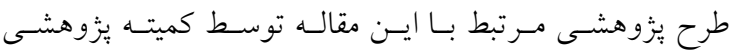

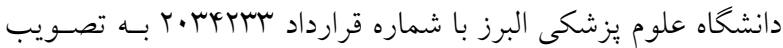
رسيده است.

\section{يافته ها}

شركت كنند كانه900 نفر از بيماران ا تا ه 90 ساله ترخيص شـده

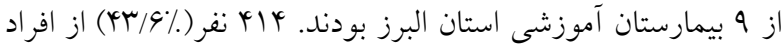

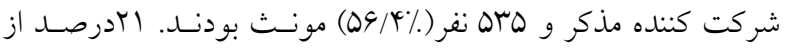
افراد شركت كننده بيسواد بوده، 19/1 درصـــ داراى تحصسيلات در سطح ابتدايى و نهضت بودند و \% \% ن نيـز تحصسيلات خــود را در حد راهنمايى و دبيرستان ذكر كرده بودند.

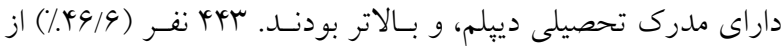

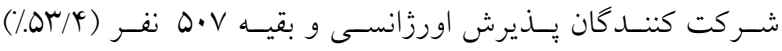
ئذيرش غير اورزانسى داشتند.

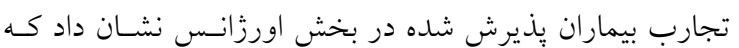

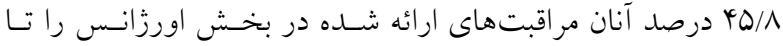

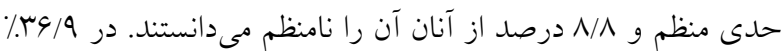
موارد بيش از يكساعت يس از ورود به اورزانسس بسـترى صـورت

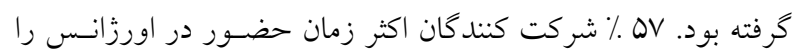

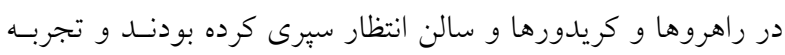
دريافت اطلاعات كامـل از شـــايط بز شـكى و وضـعيت درمـان در بخش اورزانس تنها در س/r/\% موارد وجود داشت. ץ \& درصد بيماران غير اورزانسس (الكتيـو ) نيازمنـد بسـترى،

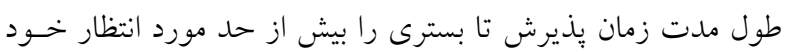

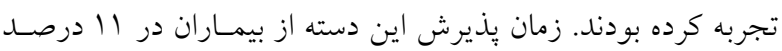
موارد يك بار يا بيشتر تغيير كرده بود. تجربه اين گروه نشان داد كـه
فرايند مراقبت مىتواند انجام كيرد كه در هر دو صورت مىتسوان از

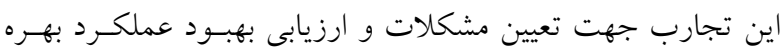
0. جهت ارزيابى خدمات ارائه شــده در بيمارسـتانهـا و رضـايت بيماران مطالعات زيادى انجام شده است ولى تنهـا يـك مطالعـه در كشور ما در رابطه با تجارب بيماران در خصوص بسترى بيمارستانى انجام شده است و اكثر مطالعات قبلى بر ميزان رضـايت بيمـاران از خدمات تاكيد دارند كه داراى نقايصسى در زمينـه عمليـاتى شـدن و استفاده به عنوان راهنمايى براى ايجاد تغييرات مسىباشــند. از اينـرو مطالعـه حاضـر در زمينـه بررسـى نظــرات و تجربيـات بيمــاران درخصوص بسترى بيمارستانى در9 بيمارستان دانشخاهى استان البرز و در قالب يكى مطالعه مقطعى - توصيفى انجام كرفتـه اسـت. اميـد است بتوان از نتايج آن براى مشخص شدن نقاط قابل بهبود و آغـاز برنامه هايى براى ارتقاى كيفيت خدمات بسترى بيمارستانى استفاده

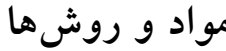

جامعه مورد بررسى در اين مطالعسه مقطعى (Cross Sectional) شامل ه00 نفر از بيمارانى بودند كه يك دوره بسترى بيمارسـتانى را يشت سر گذاشته و از يكى از بيمارستانهاى دانشخاهى اسـتان البـرز در طى مطالعه ترخيص شده بودند. نمونه كيرى بـه روش طبقـه اي اي

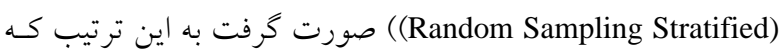
در هر بيمارستان نمونهها به نسبت فراوانى بيماران ترخيص شــده از

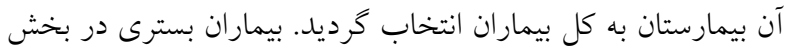
هاى ويزه (آى سى يو و سى سى يو) و بيمار ان بخش هاى اعصـاب بيماب و روان از مطالعه كنار كذاشته شدند. يرسشنامه مورد استفاده در اين مطالعه شامل دو بخش مى باشـــ. بخش اول حاوى سؤالات مربـوط بـه بررسسى تجـارب بيمـاران از بسترى بيمارستانى بوده كه برگردان فارسى برسشنامه بِيكر مى باشـــ

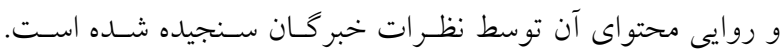
همجنين در بررسى بيش آزمون بر روى · ب نمونه، آلفـاى كرونبـاخ

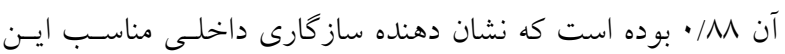
سؤالات بوده است. بخـش دوم سـؤالاتى درخصـوص مشخصـات 
ساير مراقبت ها و درمانهاى انجام شده براى بيمار در جدول او ب

$$
\text { آورده شده است. }
$$

در اين مطالعه تجربه بيماران نشان داد كه حريم خصوصى در زمان صحبت در مورد بيمارى در مورد \ل ادرصد بيماران و نيـز رعايـت حريم خصوصى در معاينه و انجام خدمات يرسـتارى در خصسوص

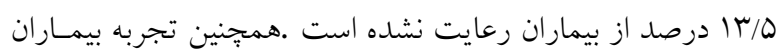

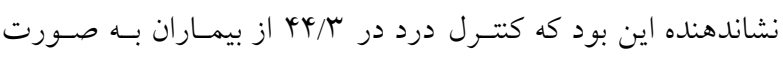
كامل انجام شده است. سايرتجارب بيمار ان در زمينـه مراقبـتهـاى كلى و ترخيص در جدول ب آورده شده است.
در مورد 1/•0 درصد از شركت كنند كان يذيرش تاحدى منظم و در

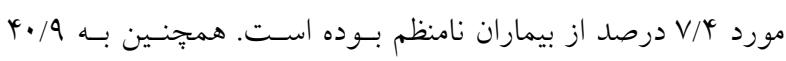
درصد از بيماران اطلاعاتى در مورد بيمارسـتان و بسـترى شــدن در زمان بذذيرش ارايه نشده بود.

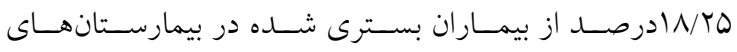
دانشخاهى استان البرز تجربه بسترى در اتاقهاى يـك و دو نفـره را داشتند و rV/T درصد از افراد نيز تجربه بسترى در اتاق با فـرد غيسر همجنس را داشتند. ساير تجارب بيماران در مورد محيط و امكانسات بيمارستانها و نيز تجـارب آنـان در خصـوص بز شـك و يرسـتار و

جدول ا: تجارب بيماران در حيطههاى مختلف

\begin{tabular}{|c|c|c|}
\hline 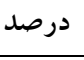 & 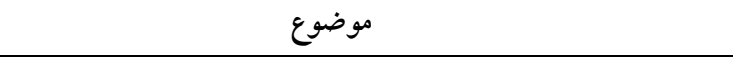 & تجارب بيماران در هر حيطه \\
\hline$r q / 1$ & مناسب بودن كيفيت غذاى بيمارستان & محيط و امكانات بيمارستان \\
\hline$\wedge \cdot$ & مناسب بودن زمان توزيع غذا & \\
\hline $9 Y / 1$ & مناسب بودن نحوه توزيع غذا & \\
\hline$\Lambda \cdot / \Lambda$ & مناسب بودن مقدار غذا & \\
\hline$\Lambda F / Q$ & وجود سرمايش و گرمايش مناسب & \\
\hline$\wedge \psi / \Lambda$ & تميزى بخش محل بسترى & \\
\hline $\mathrm{V} / \mathrm{A}$ & تميزى توالت و حمام & \\
\hline TA/V & امكان استفاده از تلويزيون سالم و قابل استفاده & \\
\hline DF & امكان استفاده از تلفن سالم و قابل استفاده & \\
\hline$Y \Psi / 9$ & وجود زنخ احضار سالم يرستارى و حضور به موقع يرستار & \\
\hline$\notin V / \Lambda$ & مزاحمت ناشى از سر وصدا م & \\
\hline ro & عدم وجود يك يزشك مشخص براى درمان & يز شيكان \\
\hline$\notin V / V$ & دريافت هميشخى پِاسخ قابل درى به سوالات & \\
\hline$T M / N$ & عدم امكان صحبت با يزشك در مورد نخرانى ها & \\
\hline$K r / 1$ & عدم امكان دسترسى كاملاً آسان به يزشك ع ع & \\
\hline$\Lambda r / \Lambda$ & عدم احساس رنجش از صحبت هاى يزشكان در حضور بيمار & \\
\hline $\mathrm{m} / \mathrm{\Lambda}$ & وجود يك برستار مشخص براى درمان & 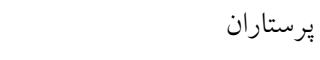 \\
\hline IV/D & عدم امكان صحبت با برستار در مورد نكرانى ها & \\
\hline $4 \varphi / 9$ & دريافت هميشخى پياسخ قابل درك به سوالات بيمار & \\
\hline$V \varphi / 4$ & عدم احساس رنجش بيمار از صحبتهاى يرستاران در حضور بيمار & \\
\hline$\Delta T / \mathcal{C}$ & برخورد و رفتار كاملاً مناسب يرستاران & \\
\hline IV $/ \mathrm{T}$ & عدم دريافت توضيحات قبل از انجام اقدامات يرستارى & \\
\hline $19 / \pi$ & دريافت اقدامات يرستارى همراه ناراحتى & \\
\hline
\end{tabular}


جدول ؟: ساير تجارب و تجارب ترخيص

\begin{tabular}{|c|c|c|}
\hline$\Lambda \cdot / r$ & عدم وجود تناقض در صحبتهاى كاركنان & مراقبت از بيمار \\
\hline $\mathrm{rV} / \mathrm{Q}$ & عدم امكان سوال نزديكان بيمار از يزشك & \\
\hline$\Delta 9$ & عدم امكان يِيدا كردن فردى ياسخكو در بيمارستان (در صورت بروز مشكل) & \\
\hline$r \cdot 14$ & 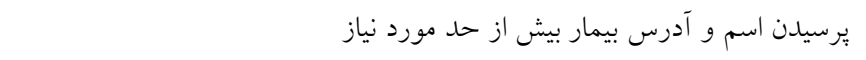 & \\
\hline$r \Delta / 1$ & عدم وجود كمك به موقع در هنگام خوردن غذا & \\
\hline$r \Lambda / r$ & عدم انجام به موقع راديولوزى و اسكنها در بيمارستان & \\
\hline rq/1 & نياز به خروج از بيمارستان براى تكميل بخشى از درمان & \\
\hline$v \cdot / 0$ & دريافت توضيح در مورد علت مصرف داروها & ترخيص از بيمارستان \\
\hline$\mu \varphi / r$ & عدم دريافت توضيح درخصوص عوارض داروها & \\
\hline$r / / r$ & عدم دريافت توضيح در خصوص علايم خطر بيمارى يا درمان & \\
\hline rV & عدم دريافت اطلاعات لازم و كامل توسط نزديكان بيمار در جهت كمك به بهبود & \\
\hline & بيمار & \\
\hline rI & كفتكو در مورد نياز به خدمات اجتماعى و درمانى در منزل & \\
\hline$\checkmark 1 / 9$ & عدم تأخير در زمان ترخيص & \\
\hline
\end{tabular}

زمينه زمان انتظار در حد خوب بود و تجارب V9 درصد بيمـاران از

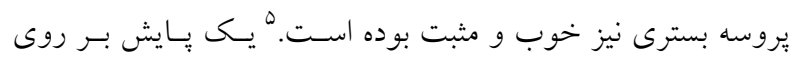

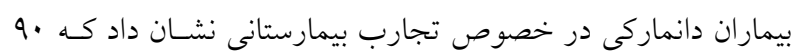
درصد بيماران در خصوص يروسـه بسـترى بيمارستانى نظـر كلى

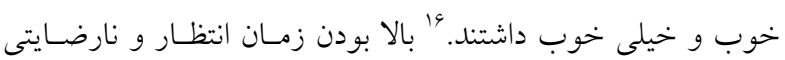

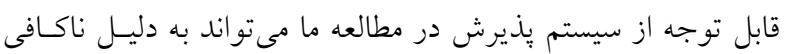
بودن نيروى انسانى و يا مديريت ضعيف در اين سيستم باشد.

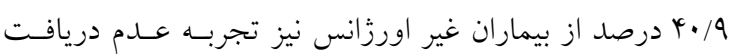
اطلاعات را در مورد بيمارستان و بسـترى شــن در زمـان يـذيرش

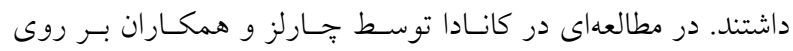

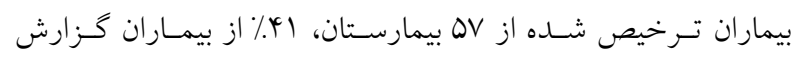

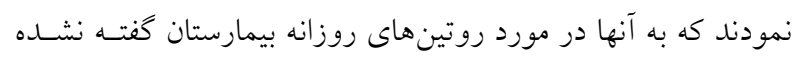
بود " كه مشابه نتيجه به دست آملده در اين مطالعه مى باشد.

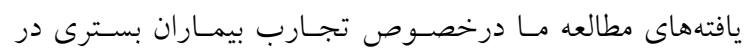
بيمارستانهاى دانشخاهى اسـتان البـرز در مـورد محسيط و امكانـات

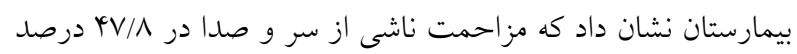
از شركت كنند كان تجربه شده بود. وجود زنخ احضار يرستار سالم

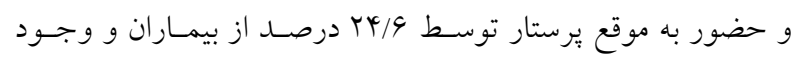

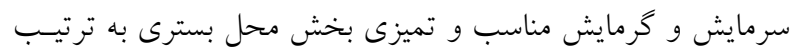

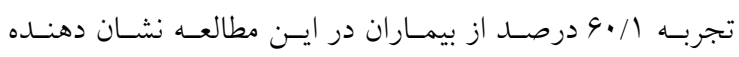

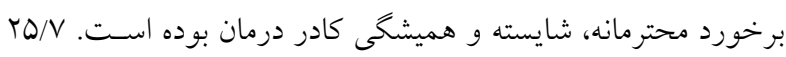

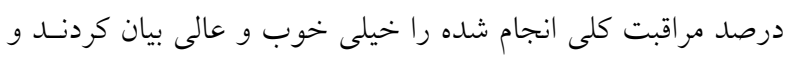
r/V

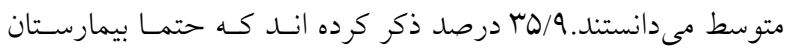
محل بسترى خود را به ديخران توصيه مى كنند و ب/ آ درصــ ذكـر

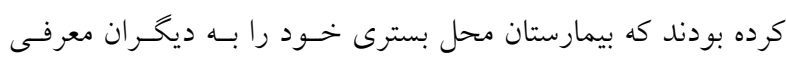
نمى كنتد.

\section{بحث و نتيجه گيرى}

نتايج اين مطالعه نشان داد كه بيش از نيمى از بيماران بسترى در

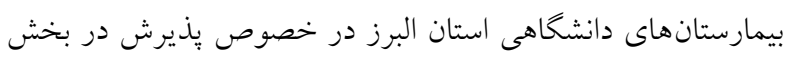

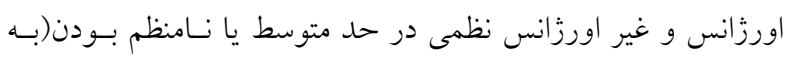

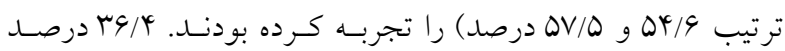
بيماران غير اورزانس (الكتيو) نيازمنـــ بسـترى، طـول مـــت زمــان يذيرش تا بسترى را بيش از حد مورد انتظار خود تجربه كرده بودند

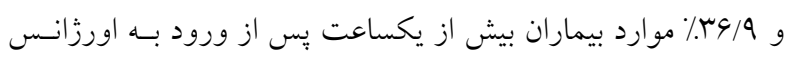

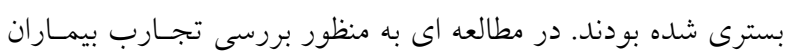

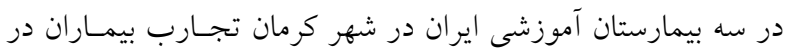


برخورد محترمانه، شايسته و هميشخى كادر درمان بود.

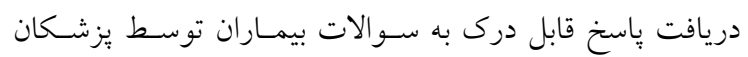

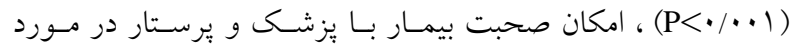
نكر انى هايش، امكان دسترسى كـاملاً آسـان بـه يزشــ در مـوارد بسترى اورزانسى كمتر از موارد غير اورزانسى بوده و اين تفـاوت از ازئر

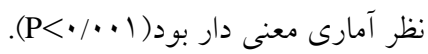
در مطالعه اميراسماعيلى و همكاران در كرمان تجـارب بيمـاران در زمينه خدمات بالينى در حد خوب و در مورد دوره درمان نسبتاً

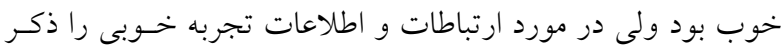
نكرده بودند. در اين مطالعه ؟^م درصد بيمار ان مى دانستند كه سـوال

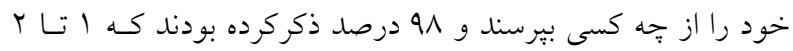

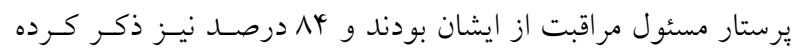

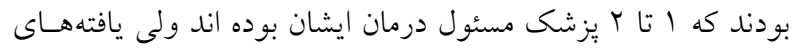

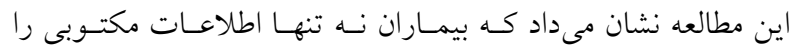

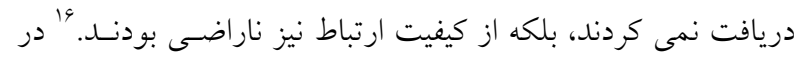

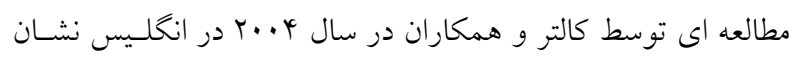

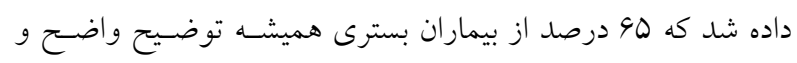

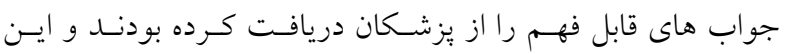

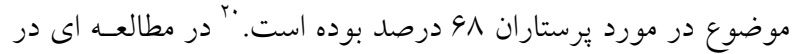

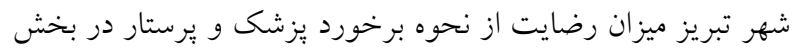

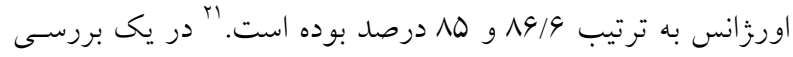

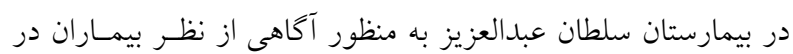

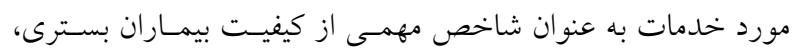

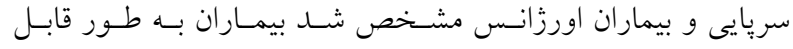

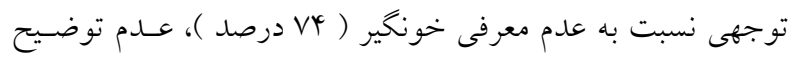

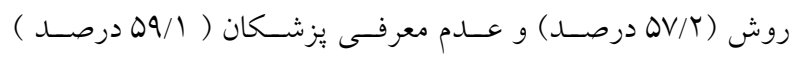

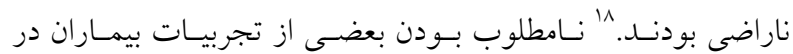
مطالعـه حاضـر در مقايسـه بـا مطالعـات مـورد مقايسـه مسى توانـــ نشاندهنده عدم توجه به حقوق بيماران از سوى برسنل و يا آموزش

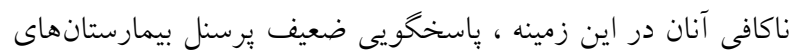

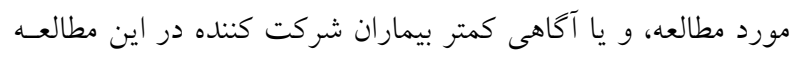
از حقوق خود نسبت به شـركت كنــدكان مطالعـات مـورد مقايسـه

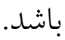
به طور كلى يافتهاى اين مطالعه نشاندهنده تجارب مطلوب تر

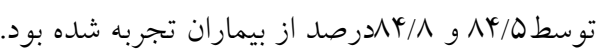
در يك بررسى در بيمارستان سلطان عبدالعزيز بـراى آخـاهى از

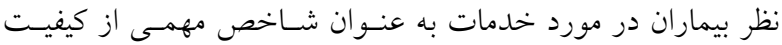

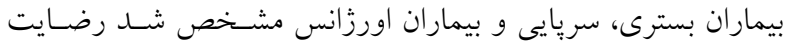
قابل توجهى از آسايش اتاق (NN/ه درصــ)، درجـهـ حسرارت اتـاق

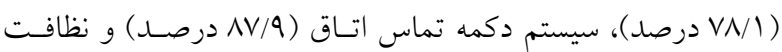
اتاق (VQ/9 درصد) وجود داشت ^ تجارب بيمـاران سـه بيمارستان آموزشى كرمان نيز در زمينه محيط فيزيكى نسبتاً خوب بوده است. 19

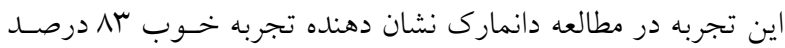

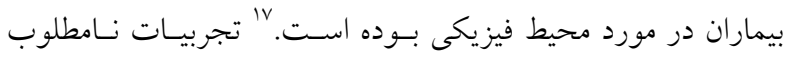
بيماران در اين مطالعه در خصوص بعضى از ابعاد محيط فيزيكسى و

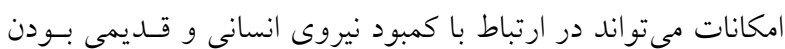
زير ساختهاى موجود باشد.

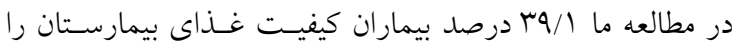

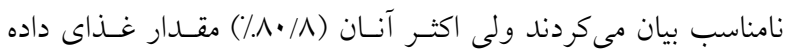

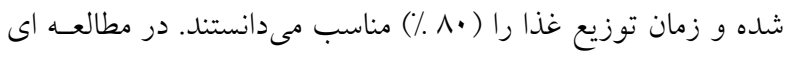

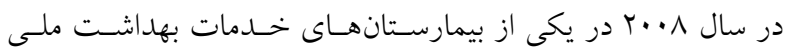

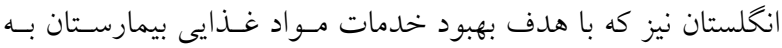
صورت كمى و كيفى انجام شده بود، تمهاى استخراج شــه "غـذا" هات بيشتر از " مقدار غذا " بيان شده بود. 19

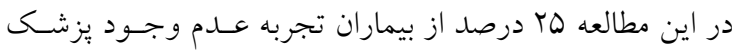
مشخص و / / مب درصد تجربه عدم وجود يرستار مشخص در زمينه

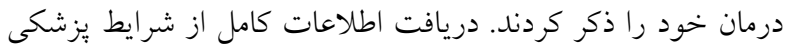

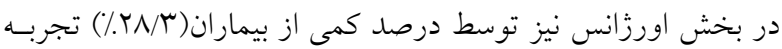

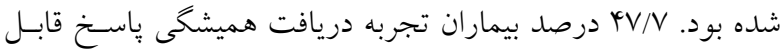

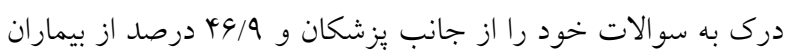
اين تجربه را درخصوص يرستاران داشتند. امكان صحبت در مـورد

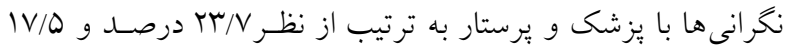

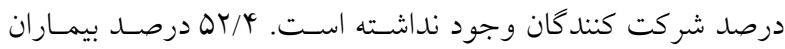
رفتار يرستاران را كاملا مناسب ارزيابى كرده بودند و N N/T درصد از

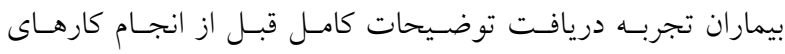

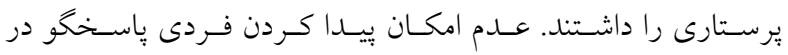

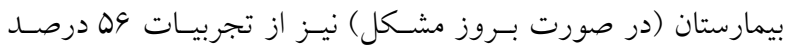
بيماران بدست آمد. تجربه / •9 درصد از بيماران نيـز نشـان دهنـــه 
اين زمينه و نيز توانمندسازى آنان براى ايجاد ارتباطـات مـؤثرتر بـاــا

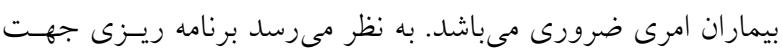

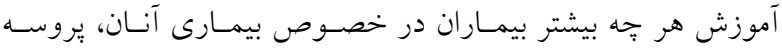
درمان، داروهاى تجـويز شــهـ و عـوارض آنهـا و نيـز بهبـود زيسـر ساختهاى موجود در بيمارستان و افزايش نيروهاى انسـانى جهـت بهبود تجربيات بيماران از سيستم بذيرش و نيز محيط فيزيكى مـؤثر باشد. همجِنين اهميت موضوع مشـترى مـدارى و افـزايش آكـاهى و دسترسى به اطلاعات مشتريان سيسـتم سـلامت موضـوع توجـهـ بـهـ تجارب بيماران و برنامه ريزى جهت رفع نـواقص و بهبـود كيفيـت خدمات سلامت را دوجندان كرده است. مسئله توجه بـه تجربيـات

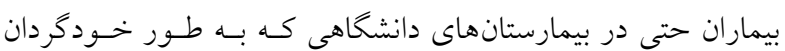

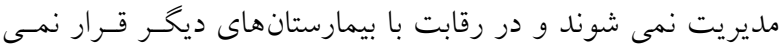
كيرند نيز از جهت بهبود كيفيت ارائسه خــدمات و رضـايت بيمـاران حائز اهميت مىباشد. بديهى است تنها يايش تجارب بيماران كافى نبوده و براى تداوم

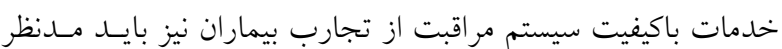

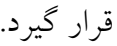

\section{تشكر و قدرداني}

تيم تحقيق بر خـود لازم مسىدانــــ از تمـامى رؤســا و يرسـنل

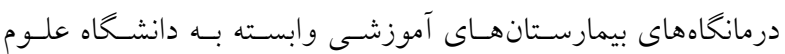
يزشكى البرز و نيز كليه بيماران بسترى حاضر در اين مطالعه تشـكر

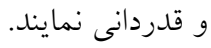

\section{References}

1. Jaafaripooyan E. Potential pros and cons of external healthcare performance evaluation systems: real-life perspectives on Iranian hospital evaluation and accreditation program. Int $\mathrm{J}$ Health Policy Manag. 2014;3(4):191-8. (In Persian).

2. Khaki M, Kargar M, Parham M, Mohebi S. Survey the quality of provided services in out-patient's clinics of shiraz training hospitals based on the model of SERVQUAL in 2014. IJNR. 2015;10(3):81-8. (In Persian).
بيمـار ان بسترى غيراورزانسى از يزشـكان و يرسـتاران نسـبت بـهـ بيماران بسترى اورزانسى مىباشد در حاليكه اولين تجربـه بيمـار از بيمارستان اغلب مربوط به بخش اورزانس مىباشـــ و بيمـاران ايسن بخش نياز فورى به مراقبتهاى درمانى دارند، لذا موضسوع تجـارب مطلوب بيماران از اين بخش حائز اهميت بيشترى مىباشد.

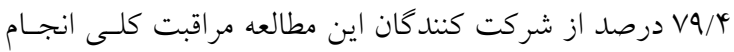
شده را در حد خوب و بالاتر ارزيابى كردند. يافتههاى مطالعه اى كه توسط جنكينسون و همكاران بر روى بوه بيمار ترخيص شـده از

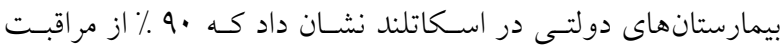
بيمارستانى رضايت داشتند." همجنين مطالعه كل افروز و همكـاران

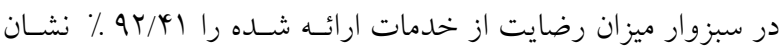

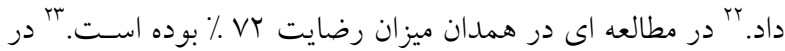

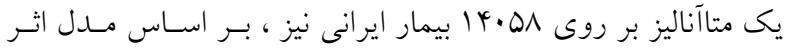

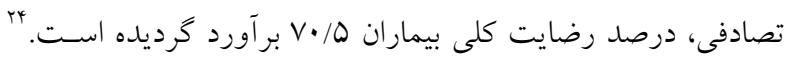
ه/ه درصد ذكر كرده اند كه حتما بيمارستان را به ديخـران توصسيه مسى كنـــد. درمطالعسه اى كـه توسطط سـيف ربيعسى و همكسـاران در

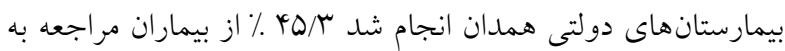

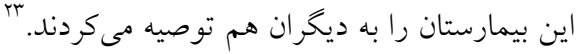
اكر جه تاكنون اقداماتى كه در زمينه بهبود رضـايت بيمـاران در بيمارستانها صورت گرفته است، روى تجارب بيماران نيز تـأثيرات مطلوبى داشته ولى نتايج مطالعه حاضر نشان دهنده عدم توجه ويـزء بيمارستانهاى مورد مطالعه به موضوع تجربيات بيمار ان و استفاده از

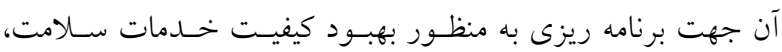

نتايج اين مطالعه نشان مىدهد جهـت بهبـود تجـارب بيمـاران، توجه و احترام به حقوق بيماران و آموزش برسنل بيمارسـتانهـا در

3. Tabibi SJ, Nasiripour AA, Hessam S. Factors Affecting Customer Orientation in Iranian Hospitals. Int J Manag Bus Res. 2011;1(1):9-14.

4. Rabert AS. Making the transformation to a customerservice orientation. 2012;7(1).

5. Amiresmaiil M, Moosazadeh M, Hasani Sadi E, Ebrahimisirizi H. Study of patient experiences at three Iranian teaching hospitals2010. Al Am een J Med Sci. 2013;6(2):138-43. 
6. Carr NG. Marketing: The Economics of Customer Satisfaction. Harvard Business Review 1999; 77(2):15-8.

7. Tabibi J. TQM in Health Care System. 2 ed. Tehran: Jahan Rayne; 2001.[In Persian]

8. Heidegger T, Saal D, Nuebling M. Patient satisfaction with anesthesia care: what is patient satisfaction, how should it be measured, and what is the evidence for assuring high patient satisfaction? Best Pract Res Clin Anaesthesiol. 2006;20(2):331-46.

9. Elleuch A. Patient satisfaction in Japan. Int J Health Care Qual Assur. 2008; 21(7):692-705.

10. Jenkinson C CA, Bruster S, Richards N, Chandola T. . Patients' experiences and satisfaction with health care: results of a questionnaire study of specific aspects of care. Qual Saf Health Care. 2002;11(4):335-9.

11. Almeida RS, Bourliataux-Lajoinie S, Martins M. Satisfaction measurement instruments for healthcare service users: a systematic review. Cad Saude Publica. 2015 31(1):11-25.

12. Defining Patient Experience: The Beryl Institute Website; 2014 [cited 2016 Dec 20 ]. Available from: http://www.theberylinstitute.org/?page=DefiningPatientE xp. .

13. Jason A. Defining patient experience. Patient experience journal. 2014;1(1):7-19.

14. Doyle C, Lennox L, Bell D. A systematic review of evidence on the links between patient experience and clinical safety and effectiveness. BMJ Open. 2013: 001570

15. Jenkinson C, Coulter A, Bruster S, Richards N, Chandola T. The Picker Patient Experience Questionnaire: development and validation using data from in-patient surveys in five countries. First published online:. 1 October 2002:353-8
16. Østerbye T, Sevaldsen J, Skjødt Hansen K. Patient's experiences in Danish hospital 2006 [cited 201615 Dec]. Available from: RL:http://www. patientoplevelser.dk /log/medie/Rappor ter/Survey_2006_english.pdf 15.

17. Charles C, Gauld M, Chambers L, O'Brien B, B. HR, Labelle R. How was your hospital stay? Patients' reports about their care in Canadian hospitals. CMAJ. 1994;50(11):1813-22.

18. Alaloola NA, Albedaiwi WA. Patient satisfaction in a Riyadh tertiary care centre. Int J Health Care Qual Assur. 2008;21(7):630-7.

19. Johns N, Hartwell H, Morgan M. Improving the provision of meals in hospital. The patients' viewpoint. Appetite. 2010;54(1):181-5

20. Coulter A. Trends in patient experience of the NHS. Picker institute 2005. 31-4.

21. Soleimanpour H, Gholipouri C, Salarilak S, Raoufi P, Rajaei Ghafouri R, Pouraghaei Mea. Assessment Of Patient Satisfaction With Emergency Department Services In Imam Khomeini Hospital, Tabriz, Iran. Urmia Medical Journal. 2012;23(1):22-31.

22. Golafrooz SM, Rahnama RS, Behnam VH, Shirzadeh E. Study of the satisfaction rate of patients hospitalized at Sabzevar hospitals in 1380-81. Journal of Sabzevar School of Medical Sciences. 1382;10(1):40- 51. [In Persian].

23. Seyf RM, Shahidzadeh MA. Patient satisfaction: A study of Hamedan teaching and general hospitals. PAYESH.5(4):271-27. [In Persian].

24. Moosazadeh M, Nekoei-moghadam M, Amiresmaili M. Determining the Level of Hospitalized Patients Satisfaction of Hospitals: A Systematic Review and Meta-Analysis. Jhosp. 2013;12(1):77-87. 